Geografia e Ordenamento do Território, Revista Electrónica

Centro de Estudos de Geografia e Ordenamento do Território

http://cegot.org

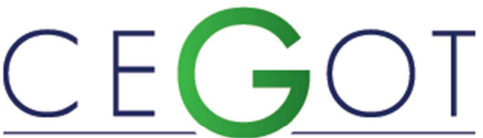

Centro de Estudos de Geografia e Ordenamento do Território
ISSN : 2182-1267

Farinha-Marques, P.

Departamento de Geociências, Ambiente e Ordenamento do Território, Faculdade de Ciências, Universidade do Porto pfmarque@fc.up.pt

Fernandes, C.

Departamento de Geociências, Ambiente e Ordenamento do Território, Faculdade de Ciências, Universidade do Porto cofernandes@fc.up.pt

\title{
Avaliação do património vegetal natural do Alto Douro Vinhateiro $2001-2012$
}

Referência: Farinha-Marques, P.; Fernandes, C. (2014). Avaliação do património vegetal natural do Alto Douro Vinhateiro 2001 -2012. Revista de Geografia e Ordenamento do Território (GOT), n.o 5 (junho). Centro de Estudos de Geografia e Ordenamento do Território, p. 93-115

\section{Resumo}

O Alto Douro Vinhateiro é uma paisagem cultural evolutiva viva, património mundial desde 2001. Dez anos após a distinção foi feito um estudo multidisciplinar sobre o seu estado de conservação. No trabalho que aqui se apresenta avalia-se a evolução, entre 2001 e 2012, das classes de uso do solo que codificam o património natural do ADV: Matos e Matas, Pinhais e Galerias Ripícolas. A avaliação foi feita com base em quatro locais de amostragem associados a paisagens de referência. Discute-se a incidência das transformações detetadas e as suas implicações na manutenção do caráter de mosaico da paisagem e na diversidade sensorial e ecológica.

Palavras-Chave: Alto Douro Vinhateiro, Paisagens de referência, Património Natural, Avaliação, Evolução.

\section{Abstract}

The Alto Douro Wine Region (ADV) is a World Heritage Evolutive and Living cultural landscape, since 2001. The work here presented is part of wider assessment of the property ten years after its inscription on the World Heritage's list, dealing specifically with the land use classes that encode the natural heritage of ADV: Thickets and 
Woodlands, Pine plantations and Riparian corridors. The evaluation was done on four sampling sites associated with target landscapes. The magnitude of change and their implications in the landscape character, in the ecological diversity and in sensory quality are here discussed.

Keywords: Alto Douro Wine Region, Target landscapes, Natural Heritage, Assessment, Evolution.

\section{Introdução}

\subsection{Alto Douro Vinhateiro - Paisagem Cultural Evolutiva Viva}

O Alto Douro Vinhateiro (ADV) localiza-se no coração da Região Demarcada do Douro (RDD) desenvolvendo-se linearmente ao longo das duas margens do rio Douro. Com uma área de 24600 ha, que equivale a $10 \%$ da área da RDD, o ADV corresponde ao contínuo melhor preservado de uma paisagem esculpida ao longo de séculos e que reflecte um processo singular de adaptação humana a condições naturais fortemente condicionadoras à sua fixação (Figura 1).

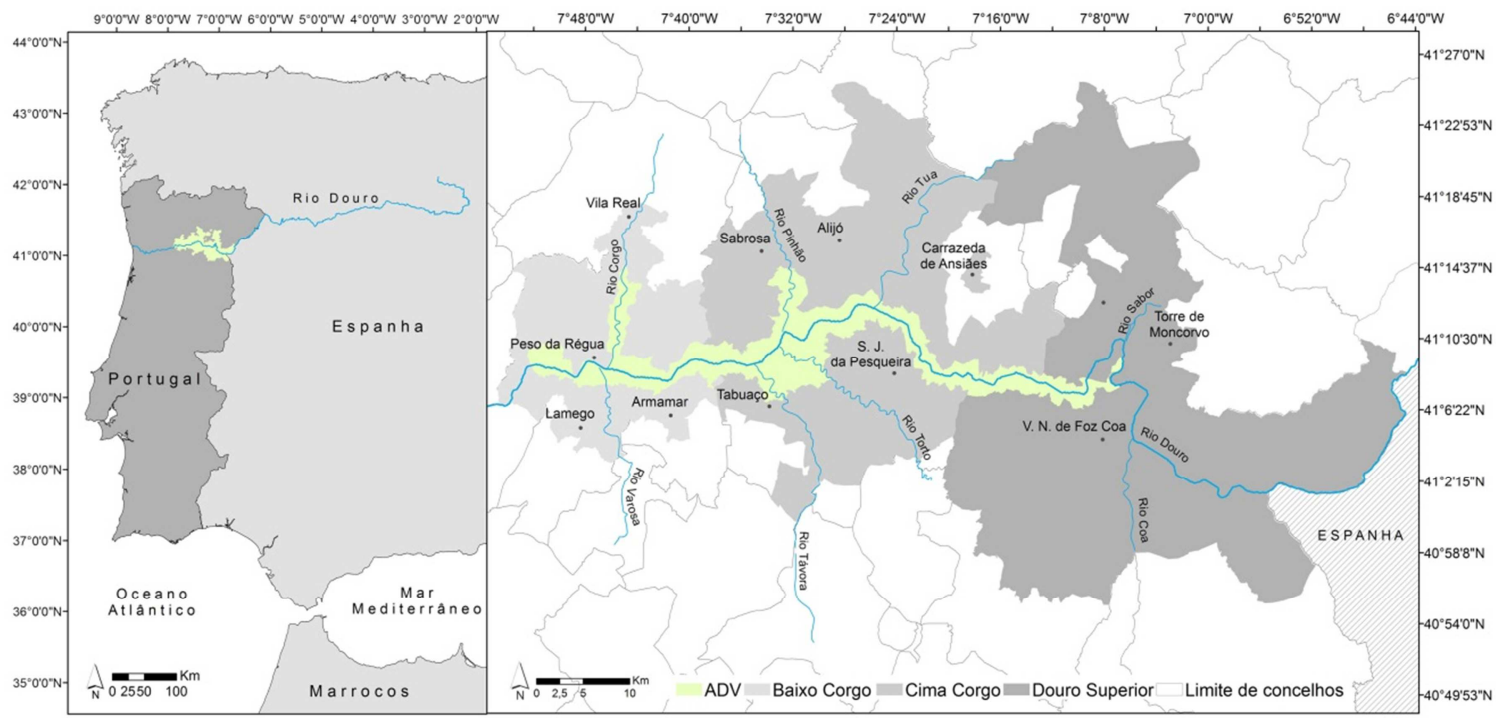

Figura 1 - Localização do Alto Douro Vinhateiro e da Região Demarcada do Douro.

O ADV integra a lista do Património Mundial da Unesco desde 2001, tendo sido classificado como Paisagem Cultural Evolutiva Viva. Isto significa que o ADV cumpre um conjunto de critérios que comprovam o seu valor universal excepcional, a sua autenticidade e que está ainda salvaguardado por mecanismos legais que asseguram a sua conservação. 
Esta distinção acarreta obrigações entre as quais o dever de assegurar a.... "proteção, conservação, valorização e transmissão às gerações futuras do património cultural e natural..." (UNESCO, 2013). Sempre que ocorrem circunstâncias excepcionais que possam afetar o estado de conservação de um bem e colocar em risco a sua integridade e autenticidade, tem início um processo de acompanhamento reativo que obriga à elaboração de estudos e produção de relatórios sobre o estado do bem ameaçado. Em 2012, em consequência do projecto da Barragem Hidroeléctrica Foz Tua, a UNESCO deliberou que o estado português deveria produzir um relatório actualizado sobre o estado geral de conservação do ADV (UNESCO, 2012).

Este trabalho resulta da investigação efetuada no âmbito deste relatório correspondendo aos estudos realizados especificamente sobre o património natural vegetal (Andresen e Rebelo, 2013; Farinha-Marques e Fernandes, 2013). Os principais objetivos foram a identificação, caracterização e quantificação das classes de uso do solo que codificam o património natural vegetal do Alto Douro Vinhateiro (ADV), para os cenários temporais de 2001 - 2012, de modo a avaliar a sua evolução.

\section{O Património Natural}

\subsection{Classes de Uso do Solo}

Em 2001, o Plano Intermunicipal de Ordenamento do Território para o Alto Douro Vinhateiro (PIOT ADV) (Bianchi de Aguiar et al., 2001) propôs duas categorias para a classificação do solo rural: espaços agrícolas e espaços naturais. Nesse documento os espaços agrícolas foram definidos como "...áreas territoriais prioritariamente de produção, onde prevalecem as culturas mediterrânicas permanentes..." e os espaços naturais como "áreas territoriais prioritariamente de conservação..." tendo sido identificadas duas subcategorias: Matos Mediterrânicos e Galerias Ripícolas.

No presente trabalho foi incluída uma terceira classe: o Pinhais, por se considerar que desenvolvem dinâmicas ecológicas próprias que deveriam ser analisadas além de contribuírem para uma maior diversidade do mosaico paisagístico. A classe Matos Mediterrânicos adopta a designação Matos e Matas, por se entender que traduz melhor a variabilidade detetada neste tipo de formações. 
Os Matos e Matas são a classe de património natural mais estruturante e emblemática ao nível da paisagem do ADV e abrange um conjunto muito vasto de formações vegetais que podem ser diferenciadas, entre outras características, com base no nível de estratificação presente. Esta classe engloba desde comunidades arbustivas constituídas por apenas dois estratos: herbáceo e arbustivo baixo, até comunidades estruturalmente complexas quanto ao número e tipo de estratos presentes. Deste modo, considerando um crescendo de complexidade estrutural este grupo inclui: 1) comunidades rupícolas, que se desenvolvem sobre substrato rochoso, e que por isso revelam dificuldade em formar um coberto contínuo e consistente; 2) comunidades arbustivas com diferentes níveis de organização e complexidade estrutural dependendo do estado sucessional e da variabilidade ambiental a que estão sujeitas; 3) comunidades de matas/bosques, ou seja, que exibem um estrato arbóreo mais ou menos denso e contínuo (Crespí et al, 2005).

As Galerias Ripícolas constituem formações arbóreo-arbustivas de extraordinária diversidade florística, associadas a linhas de drenagem natural (linhas de água permanentes ou temporárias) e a margens de albufeiras.

A classe Pinhais representa os povoamentos florestais dominados por pinheiro-bravo (Pinus pinaster) plantados para exploração de madeira. A sua capacidade para criar condições favoráveis para a ocorrência de espécies endémicas e sub-endémicas torna-os relevantes ao nível do património natural (Fernandes, 2009). 

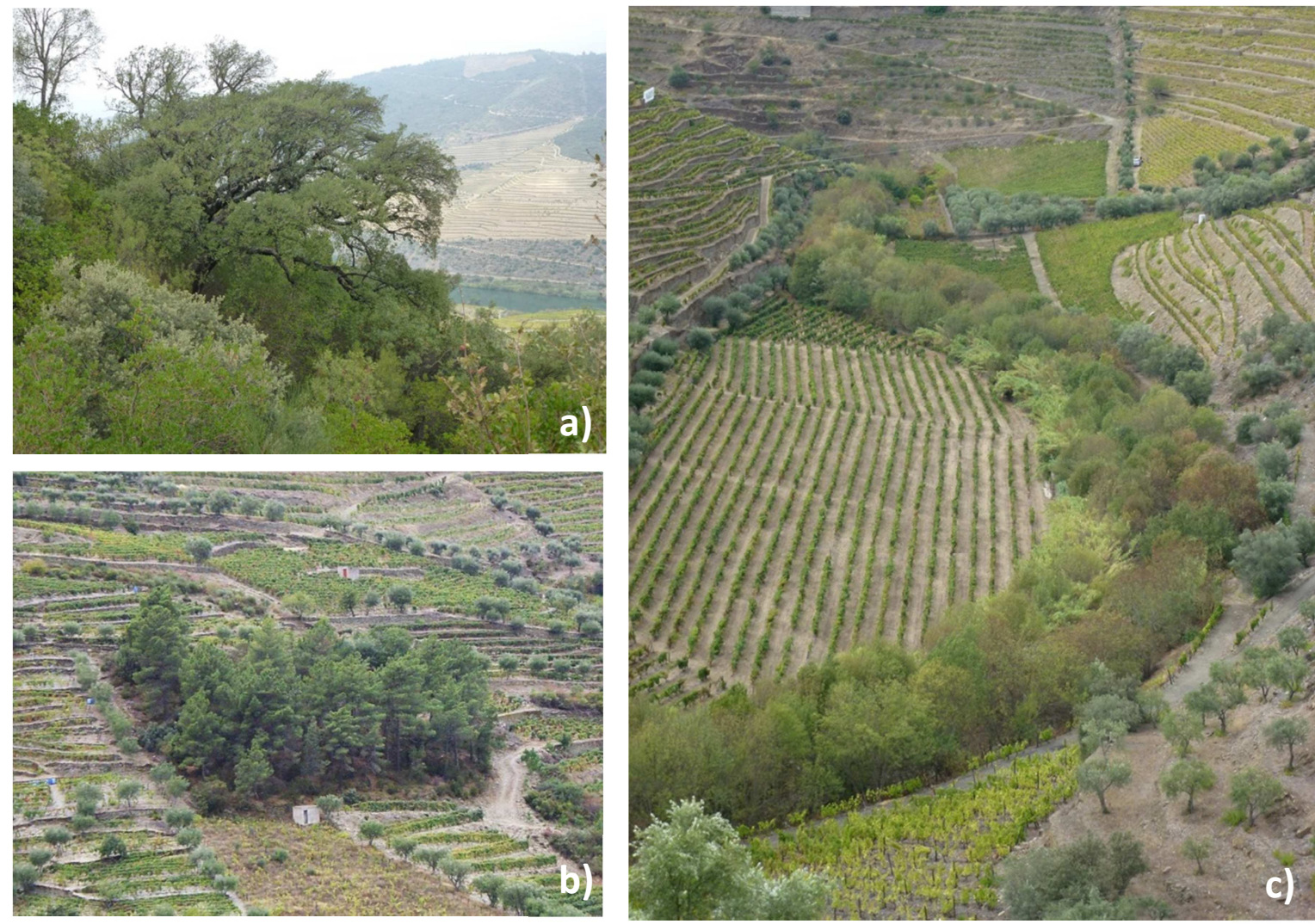

Figura 2 - a) Mato/Mata dominado por Sobreiro (Quercus suber), medronheiro (Arbutus unedo) e cornalheira (Pistacia terebinthus). b) Pequena mancha de Pinhal (Pinus pinaster) circundada por vinhas. c) Galeria Ripícola no rio Torto marcando a paisagem com a sua forma linear.

Com exceção da classe de Pinhais as restantes classes consideradas podem englobar um conjunto muito vasto de habitats, com características e valor conservacionista distintos. Deste modo, entendeu-se ser importante listar os habitats naturais do Anexo I da Diretiva 92/43/CEE (http://www.icnf.pt/) com probabilidade de ocorrência no ADV, ainda que residual.

Assim, nas manchas de vegetação designadas por Matos e Matas podem ser encontrados até 9 habitats $^{1}$ dos quais se destaca o habitat prioritário 9330 - Florestas de Quercus suber (sobreiro). Este habitat caracteriza-se pelas diversas variantes que pode apresentar em função da presença no estrato arbóreo de outros fanerófitos,

\footnotetext{
${ }^{1} 5110$ - Formações estáveis xerotermófilas de Buxus sempervirens das vertentes rochosas (Berberidion p.p.) (residual), 5210 - Matagais arborescentes de Juniperus spp. (residual), 5330 - Matos termomediterrânicos pré-desérticos, 8220 - Vertentes rochosas siliciosas com vegetação casmofítica, 8230 - Rochas siliciosas com vegetação pioneira da Sedo-Scleranthion ou da Sedo albi-Veronicion dillenii, 9330 Florestas de Quercus suber, 9340 - Florestas de Quercus ilex e Quercus rotundifolia, 9260 - Florestas de Castanea sativa (residual), 9560 - Florestas endémicas de Juniperus spp. (residual).
} 
nomeadamente: Quercus faginea subsp. Faginea (carvalho-cerquinho), Q. robur (carvalho-alvarinho), Q. rotundifolia (azinheira), Q. pyrenaica (carvalho-negral), Juniperus oxycedrus (zimbro), Fraxinus angustifolia (freixo), Pinus pinaster subsp. atlantica (pinheiro bravo), Pyrus cordata (escalheiro) e Arbutus unedo (medronheiro). A proteção e integridade destes bosques é assegurada por orlas arbustivas extremamente diversificadas constituídas essencialmente por matagais, medronhais e carrascais de azinheira. Apesar da sua presença residual no ADV, os habitats prioritários 5110 e 9560 foram incluídos pelo facto de serem habitats com uma distribuição muito reduzida o que aumenta a importância da sua conservação.

As galerias ripícolas podem incluir 3 habitats ${ }^{2:}$ sendo de salientar o habitat prioritário 91E0 - Florestas aluviais de Alnus glutinosa (amieiro) e Fraxinus excelsior (freixo). Estes bosques caducifólios não se encontram em cursos de água temporários ou de regimes torrenciais e caracterizam-se pelo seu biótopo denso e sombrio que permite o aparecimento de inúmeros fetos: Asplenium onopteris (avenca-negra), Athyrium filixfemina (feto-fêmea), Blechnum spicant (feto-pente), Dryopteris sp., Osmunda regalis (feto-real), Polystichum setiferum (fentanha).

Identificaram-se ainda vários habitats com interesse conservacionista sem enquadramento nas classes anteriores pelo que se agruparam numa classe designada Outros $^{3}$. Deste grupo constam 12 habitats relacionados essencialmente com cursos de água, charnecas e pradarias, dos quais apenas o habitat 6220 é prioritário.

\footnotetext{
${ }^{2}$ 91B0 - Freixiais termófilos de Fraxinus angustifolia (residual), 91E0 - Florestas aluviais de Alnus glutinosa e Fraxinus excelsior (Alno-Padion, Alnion incanae, Salicion albae), 92A0 -Florestas-galerias de Salix alba e Populus alba.

${ }^{3} 3150$ - Lagos eutróficos naturais com vegetação da Magnopotamion ou da Hydrocharition, 3260 - Cursos de água dos pisos basal a montano com vegetação da Ranunculion fluitantis e da Callitricho-Batrachion, 3270 - Cursos de água de margens vasosas com vegetação da Chenopodion rubri p.p. e da Bidention p.p, 3280 - Cursos de água mediterrânicos permanentes da Paspalo- Agrostidion com cortinas arbóreas ribeirinhas de Salix e Populus alba, 3290 - Cursos de água mediterrânicos intermitentes da PaspaloAgrostidion, 4030 - Charnecas secas europeias, 6160 - Prados oro-ibéricos de Festuca indigesta, 6220 Subestepes de gramíneas e anuais da Thero-Brachypodietea, 6410 - Pradarias com Molinia em solos calcários, turfosos e argilolimosos (Molinion caeruleae), 6420 - Pradarias húmidas mediterrânicas de ervas altas da Molinio-Holoschoenion, 6430 - Comunidades de ervas altas higrófilas das orlas basais e dos pisos montano a alpino, 6430 - Comunidades de ervas altas higrófilas das orlas basais e dos pisos montano a alpino, 6510 - Prados de feno pobres de baixa altitude (Alopecurus pratensis, Sanguisorba officinalis) (Residual).
} 


\subsection{Flora característica das classes patrimoniais avaliadas}

\subsubsection{Flora característica dos Matos e Matas}

A variabilidade climática registada na Região Demarcada do Douro determina, naturalmente, a distribuição da vegetação natural.

No Baixo Corgo, a frescura atlântica ainda se faz sentir permitindo a presença de sobreiro (Quercus suber) e carvalho-alvarinho (Quercus robur) nos estratos arbóreos e um elenco notável de arbustos e sub-arbustos: medronheiro (Arbutus unedo), o pilriteiro (Crataegus monogyna), o folhado (Viburnum tinus), a torga (Calluna vulgaris), a urze branca (Erica arborea), os tojos (Ulex spp.), e ainda a gilbardeira (Ruscus aculeatus), o estevão (Cistus populifolius subsp. populifolius), e o espargo-bravo (Asparagus acutifolius).

No Cima Corgo e sobretudo no Douro Superior a aspereza mediterrânica torna-se mais limitativa ao desenvolvimento vegetal e só a rusticidade da azinheira (Quercus rotundifolia) e do zimbro (Juniperus oxycedrus subsp. oxycedrus) Ihes permite resistir em tais condições. Em áreas mais circunscritas é possível encontrar outros elementos notáveis como o carvalho-cerquinho (Quercus faginea subsp. faginea), a zêlha (Acer monspessulanum) e o zambujeiro (Olea europaea subsp. europaea var. sylvestris). Nos estratos arbustivos são frequentes a cornalheira (Pistacia terebinthus), o Lentisco (Phillyrea angustifolia); o abrunheiro (Prunus spinosa), a esteva (Cistus ladanifer subsp. ladanifer), o rosmaninho (Lavandula pedunculata), o trovisco (Daphne gnidium), a roselha (Cistus albidus) e os sanganhos (Cistus salvifolius e Cistus psilosepalus).

\subsubsection{Flora característica das Galerias Ripícolas}

As condições ecológicas em que as Galerias Ripícolas se desenvolvem permitem-lhes atingir uma grande complexidade estrutural. Acompanhando os cursos de água manifestam características de bosques lineares, sobretudo quando exibem um estrato arbóreo contínuo nas duas margens. Nestes espaços desenvolvem-se espécies arbóreoarbustivas típicas como amieiro (Alnus glutinosa), freixo (Fraxinus angustifolia), ulmeiro (Ulmus minor), choupo-negro (Populus nigra), choupo-branco (Populus alba), lodão (Celtis australis), várias espécies de salgueiro (Salix atrocinerea, Salix alba ssp. vitelina, 
Salix salvifolia), sabugueiro (Sambucus nigra) e salgueirinha (Lythrum salicaria). Os salgueirais ocupam preferencialmente troços de afluentes do rio Douro onde o regime das águas é mais agressivo e os solos são mais arenosos ou pedregosos (Ribeiro, 2000; Ribeiro e Diniz, 2004).

As comunidades ripícolas, especialmente as menos perturbadas, são também muito ricas em espécies lianas herbáceas cuja presença decumbente sobre as copas das árvores confere à galeria uma aspeto particular: lúpulo-bravio (Humulus lupulus), a doce-amarga (Solanum dulcamara), a norça-branca (Bryonia dioica) e a norça-preta (Tamus communis). A hera (Hedera helix), as madressilvas (Lonicera spp.), as roseirasbravas (Rosa spp.) e as silvas (Rubus spp.) são lianas lenhosas igualmente características destes habitats.

\subsubsection{Flora característica dos Pinhais}

Em termos estruturais os Pinhais do ADV são constituídos por um estrato muscícolaliquénico, um herbáceo e um ou mais estratos arbustivos, sobre os quais se desenvolve um estrato arbóreo dominado fundamentalmente por Pinheiro bravo (Pinus pinaster).

Os estratos arbustivos que constituem o seu sub-coberto têm grande variação de fisionomia e porte em função do tipo de solos em que se instalaram e da quantidade de luz que os pinheiros deixam penetrar. No geral, o sub-coberto é dominado por nanofanerófitos com abundâncias limitadas pelo "mulch" de acículas que se forma junto ao solo. Das espécies possíveis neste estrato salientam-se as seguintes: queiroga (Erica umbellata), rosmaninho-menor (Lavandula stoechas subsp. luisieri), Halimium umbellatum subsp. viscosum, codeço (Adenocarpus complicatus), carqueja (Pterospartum tridentatum subsp. lasianthum), tojo-molar (Ulex minor), sanganho (Cistus psilosepalus), tojo-gadanho (Genista falcata), Anarrhinum bellidifolium, ansarinados-campos (Linaria spartea), Narcissus triandrus subsp. triandrus e ranúnculo-dasparedes (Ranunculus ollissiponensis subsp. ollissiponensis). Todas as espécies desta listagem têm distribuição endémica ou sub-endémica atestando o valor conservacionista destas comunidades. 

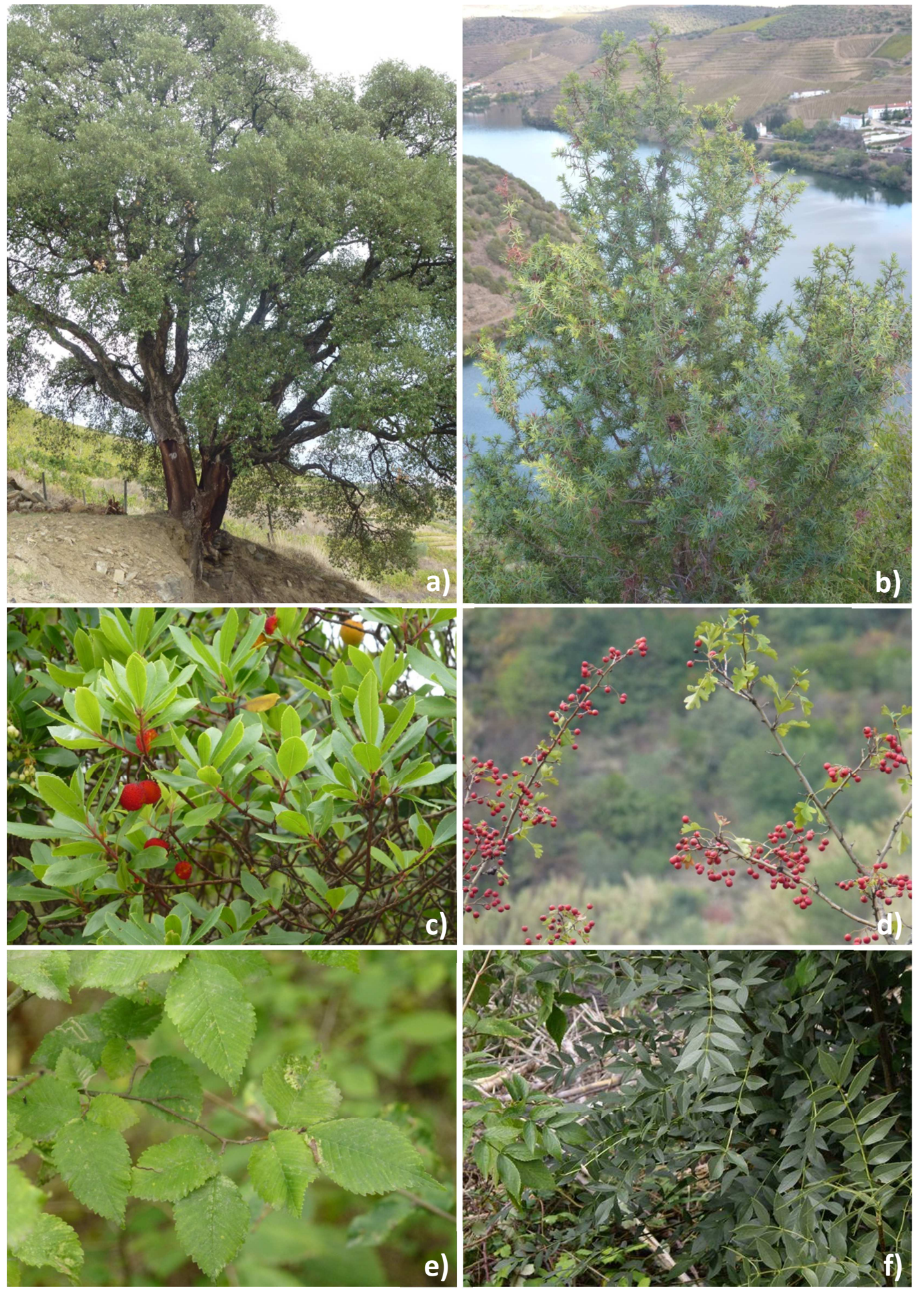

Figura 3 - Flora característica das classes analisadas: a) sobreiro (Quercus suber), b) zimbro (Juniperus oxycedrus), c) medronheiro (Arbutus unedo), d) pilriteiro (Crataegus monogyna), e) ulmeiro (Ulmus minor), f) freixo (Fraxinus angustifolia). 


\subsection{Espécies exóticas mais disseminadas}

As espécies exóticas que mais frequentemente revelam um comportamento invasor com visibilidade ao nível da paisagem são a mimosa (Acacia dealbata), a austrália (Acacia melanoxylon), a falsa-acácia (Robinia pseudoacacia) e o ailanto (Ailanthus altissima). Até ao início do séc. XX o sumagre (Rhus coriaria) foi cultivado na região de Trás os Montes e Alto Douro porque era muito utilizado na indústria de curtumes devido à riqueza em taninos. $\mathrm{O}$ abandono cultural e boa adaptabilidade à mediterraneidade transformou-o numa espécie marginal e infestante de taludes. Várias outras espécies são também comuns em margens de caminhos e em locais perturbados como por exemplo a figueira-da-índia (Opuntia ficus indica) e a baga-moira (Phytollaca americana). As margens lamacentas de alguns cursos de água encontram-se muito invadidas por canaviais de cana (Arundo donax).
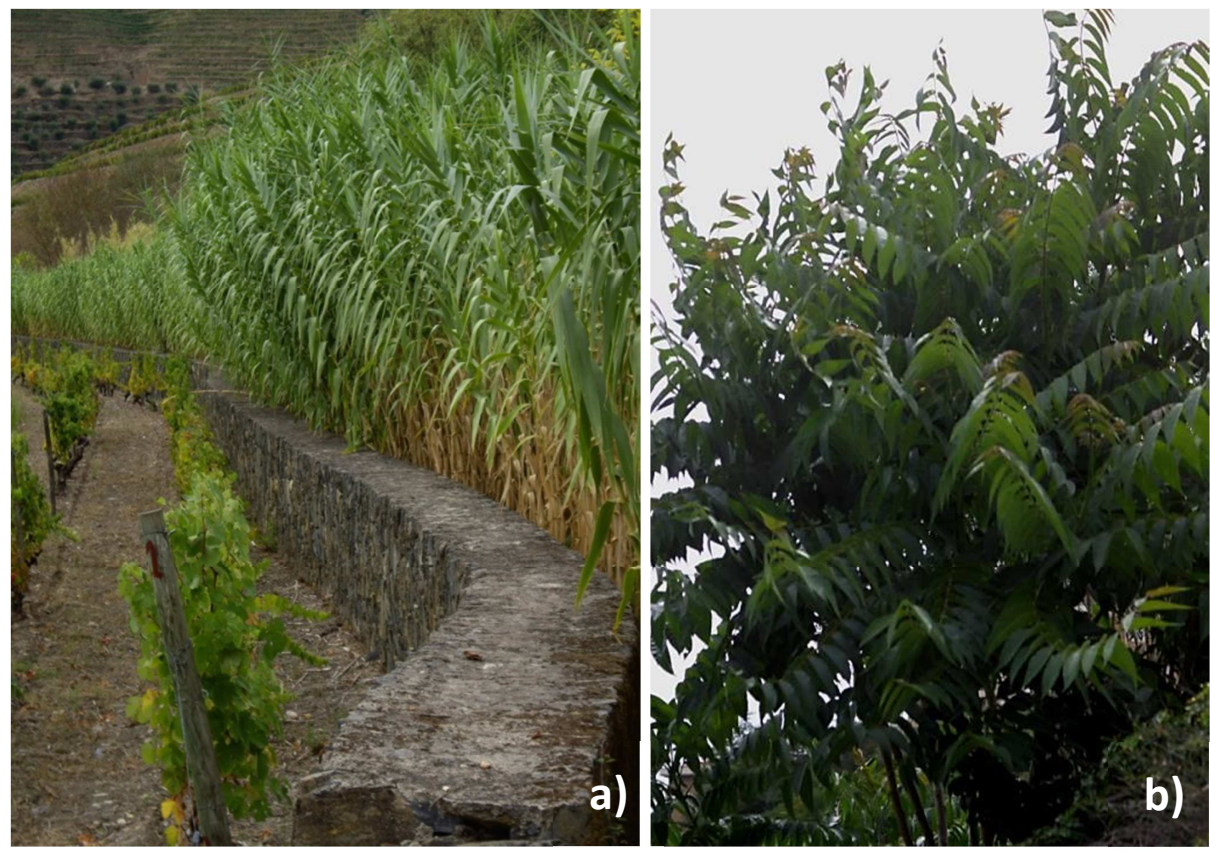

Figura 4 - a) cana (Arundo donax) e b) ailanto (Ailanthus altissima).

\section{Metodologia}

A metodologia adoptada encontra-se alicerçada em duas directrizes: 1) a avaliação das áreas de património natural ocorre em áreas de amostragem; 2) a avaliação das áreas de património natural decorre no contexto da matriz paisagística, ou seja, a classificação das tipologias de vegetação é determinada não só pela sua estrutura e composição 
florística, mas igualmente pelo seu desempenho visual enquanto elemento integrante de um mosaico paisagístico diverso e complexo. Esta metodologia encontra-se esquematizada na Figura 5.

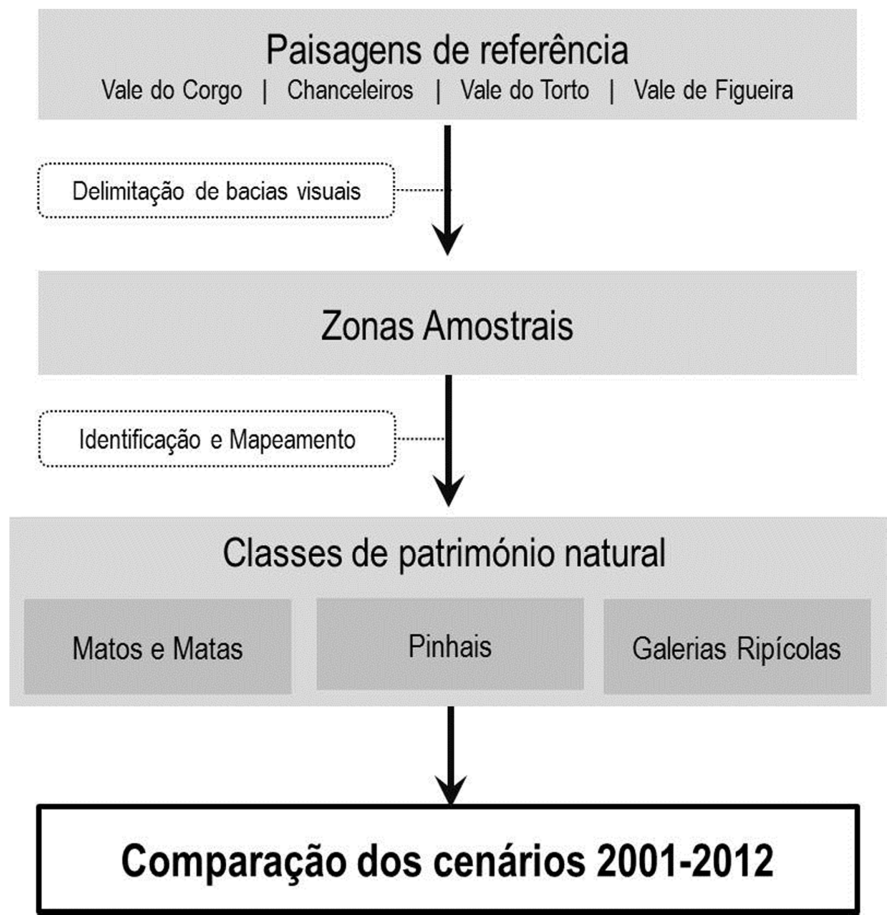

Figura 5 - Diagrama metodológico para caracterização e avaliação da evolução do património natural nos cenários temporais 2001-2012.

\subsection{Delimitação de áreas de amostragem}

Por questões operativas decorrentes de um prazo limitado para a avaliação de um bem com 24600 ha, a avaliação da evolução das manchas de vegetação natural foi feita em áreas de amostragem. Os locais seleccionados coincidem com as sub-unidades de paisagem identificadas no dossier de candidatura como representativas da "diversidade e expressão do padrão da paisagem do Alto Douro (...) (Bianchi de Aguiar et al., 2000) e que são: Vale do Corgo (492 ha) localizado no Baixo Corgo; Chanceleiros (455 ha) e Vale do Torto (458 ha) localizados no Cima Corgo e Vale de Figueira (391 ha) que representa o Douro Superior.

Dentro de cada uma das quatro paisagens de referência, os locais de amostragem foram marcados com base em bacias visuais imediatas, geradas com recurso a software ESRI's Arclnfo (ArcGIS 10.0), a partir de 3-4 pontos de observação situados ao longo das principais vias de comunicação. Os limites dessas bacias foram depois definidos pelos 
limites fisiográficos mais próximos (linhas de festo e linhas de drenagem principais) e também pelo próprio limite do ADV. Constituem na sua totalidade uma área de 1796 ha e correspondem a uma percentagem do ADV de 7,3\% da área total (Figura 6).

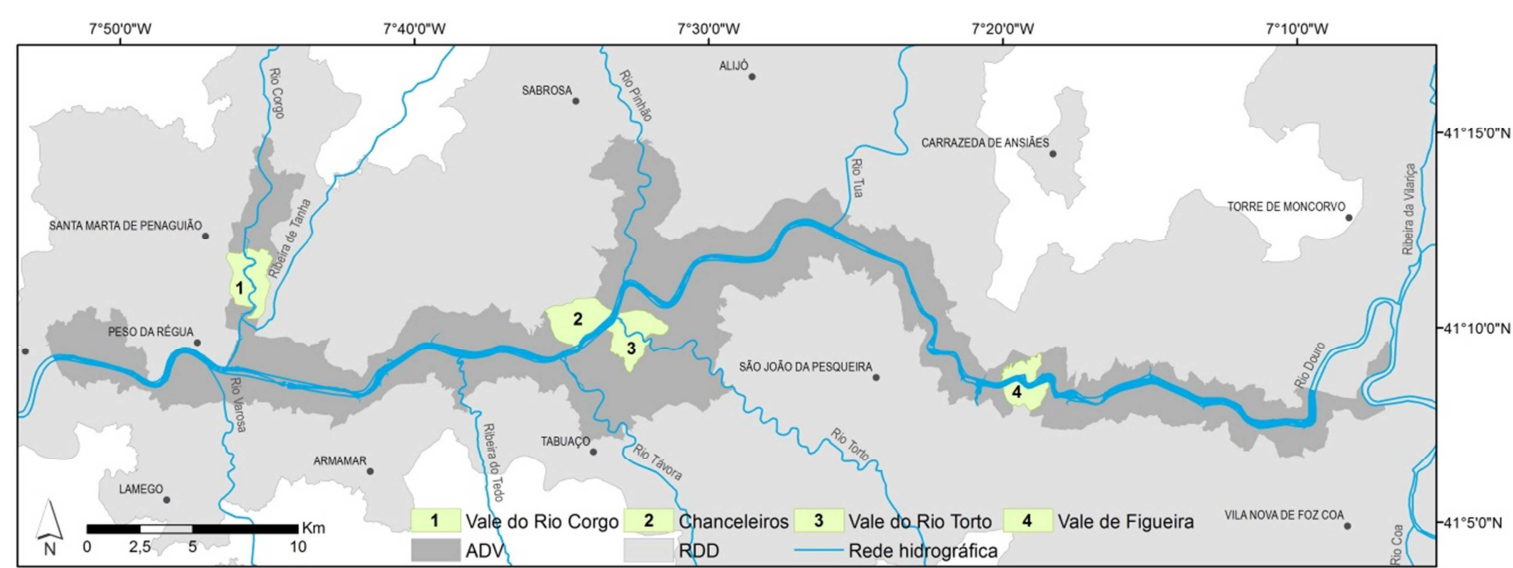

Figura 6. - Localização das paisagens de referência no Alto Douro Vinhateiro (ADV).
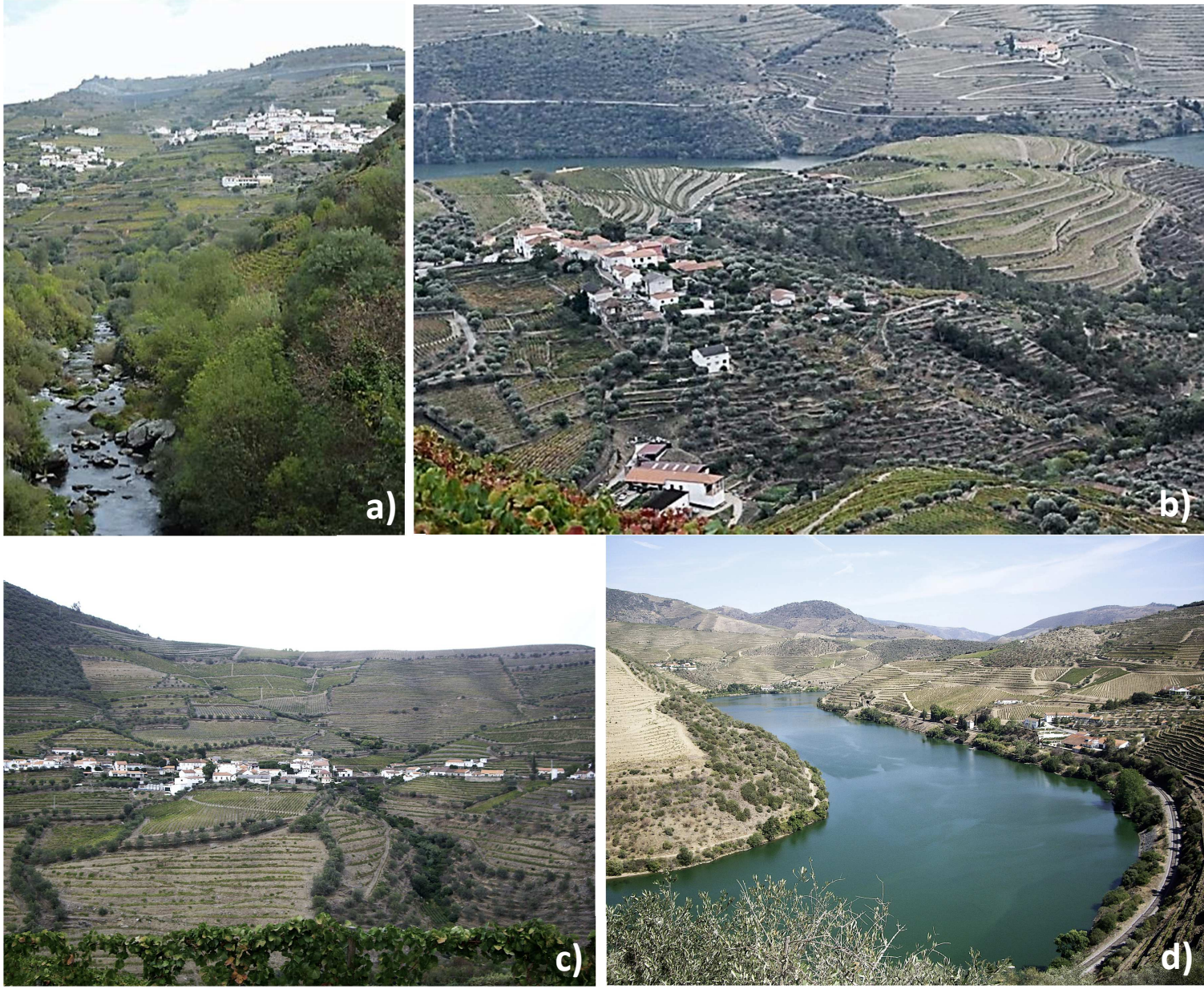

Figura 7 - Paisagens de referência: a) Alvações do Corgo, Vale do rio Corgo. b) Chanceleiros. c) Casais do Douro, Vale do rio Torto. d) Vale de Figueira. 


\subsection{Identificação e mapeamento das manchas de vegetação}

Em cada uma das áreas de amostragem foi necessário identificar as manchas de vegetação natural de cada uma das classes consideradas e avaliar a sua evolução entre os anos 2001 e 2012.

A situação de 2001 estava já expressa no Plano Intermunicipal de Ordenamento do Território do Alto Douro Vinhateiro. Contudo, a disponibilidade de tecnologias mais avançadas e de bases de dados mais rigorosas e com melhor resolução permitiram refinar a informação existente e colmatar algumas falhas. Desta forma, os resultados apresentados para o ano de 2001 incluem algumas correções que foram especialmente importantes para a avaliação da evolução das galerias ripícolas.

A situação em 2012 foi obtida por rectificação e actualização da situação de 2001 tendo por base a informação proveniente da Carta de Uso e Ocupação do Solo de Portugal Continental para o ano de 2007 (COS 2007, IGP), ortofotomapas de 2010, imagens de satélite de 2011/2012, disponibilizadas gratuitamente pelo Google Maps $^{\text {TM }}$ e BingMaps $^{T M}$, e ainda validação em campo para os casos em que persistissem dúvidas.

Para além de uma análise rigorosa à variação em área das manchas de vegetação natural o software utilizado, ESRI's Arclnfo (ArcGIS 10.0), permite a produção de mapas que ao retratarem um momento específico permitem uma análise visual imediata das alterações ocorridas.

\section{Resultados}

\subsection{Avaliação do património natural no Vale do Corgo}

O vale do Rio Corgo caracteriza-se por apresentar as principais manchas de vegetação, concentradas ao longo da linha de água principal. Estas manchas são compostas essencialmente por Matos e Matas, acompanhados, naturalmente, pelas Galerias Ripícolas. Para além deste contínuo associado ao corredor ribeirinho são ainda visíveis parcelas de pequena dimensão, muito dispersas e isoladas no mosaico paisagístico. A organização das áreas de vegetação é visível na imagem que representa o cenário de 2001 e na imagem que representa o cenário de 2012 (Figura 8).Deve salientar-se a perda 
de parcelas importantes de Pinhais, e sobretudo de Matos e Matas, na margem direita e no troço Sul do local de amostragem.

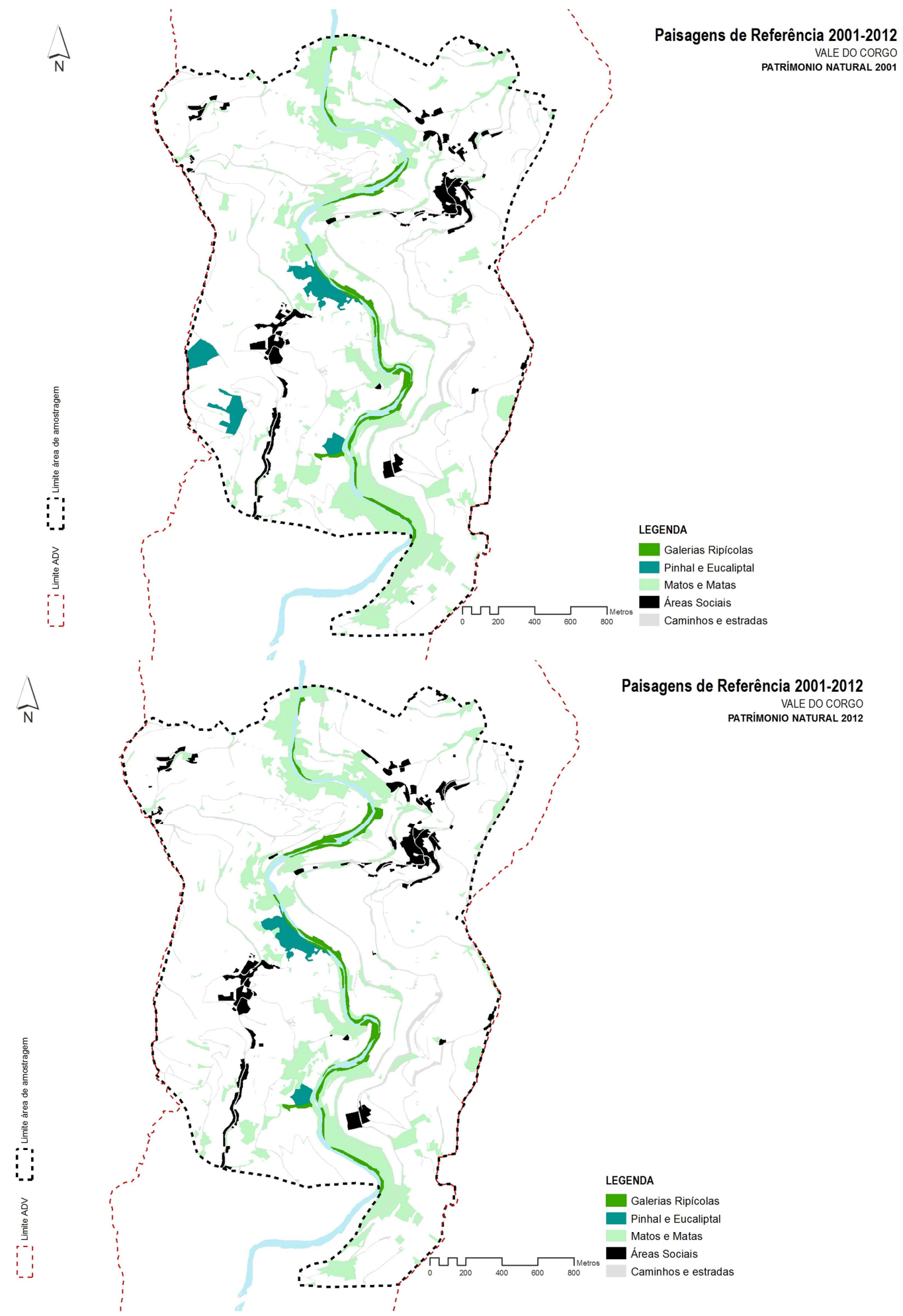

Figura 8 - Carta de património natural do Vale do rio Corgo, para o cenário temporal 2001 e 2012. 
Em termos de valores globais, o cenário de 2001 revela uma área total de parcelas de vegetação natural na ordem dos 77 ha, representando 15,6 \% da área total em estudo. Em 2012 esse valor desce para 64,7 ha, passando a representar 13,2 \% da área total. Esta perda de $2,44 \%$ da área de património natural deve-se sobretudo a um decréscimo na área de Matos e Matas, que perderam cerca de 9,3 ha (14,3\%).(Figura 9).

No vale do Corgo a diminuição da área de Matos e Matas está relacionada com plantação de vinhas novas e com o aumento da área de olival. No ADV várias manchas de Matos e Matas revelam a presença de oliveiras denunciando que se trata de olivais abandonados. Nos últimos anos, o dinamismo crescente da indústria do azeite, tem levado à recuperação de alguns destes olivais, bastando para isso uma limpeza da vegetação arbustiva que se desenvolveu em consequência do abandono. Desta forma, uma parte da redução da área de Matos e Matas também pode ser explicada pela recuperação destes olivais.

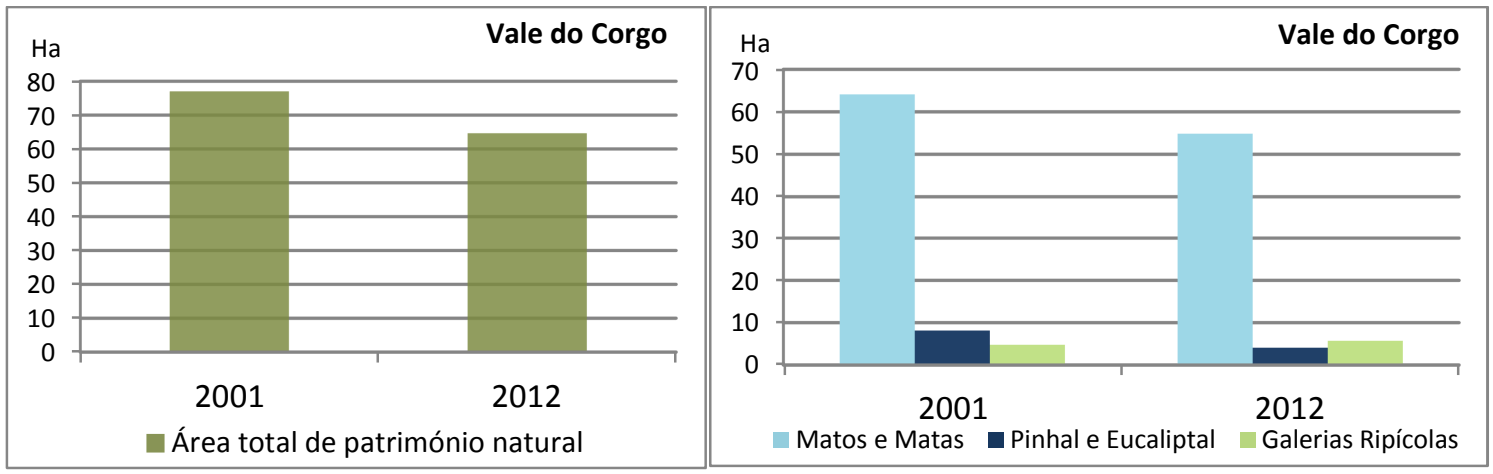

Figura 9 - 1) Variação da área total ocupada pelo património natural nos anos 2001 e 2012, no vale do rio Corgo; 2) Variação da área ocupada por cada classe de património natural nos anos 2001 e 2012, no vale do rio Corgo.

Apesar da diminuição da área de Pinhais e Eucaliptais não ser tão significativa quanto a de Matos e Matas (perderam-se cerca de 4 ha) esse valor corresponde a uma redução para metade na representatividade desta classe, neste local de amostragem. A área de Galerias Ripícolas praticamente manteve-se; o ligeiro aumento que se observa pode ser explicado pelo desenvolvimento das galerias existentes e também na possibilidade de maior rigor na delimitação das parcelas. 


\subsection{Avaliação do património natural em Chanceleiros}

Entre os anos de 2001 e 2012 perderam-se em Chanceleiros cerca de 24,7 ha (5,6\%) de área de património natural. Em 2001 as parcelas de vegetação representavam 25,4\% do local de amostragem enquanto em 2012 representam 19,8\%. A maior transformação ocorreu nas áreas de Matos e Matas que perderam cerca de $27,8 \%$ da sua expressão territorial (Figura 10). Estas perdas estão sobretudo relacionadas com plantações de vinhas novas e, em menor extensão, com a recuperação de olivais.

Tal como no vale do Corgo, também em Chanceleiros foram abandonados alguns olivais e vinhas que, em 2012 evoluíram para Matos e Matas. A área ocupada por Pinhais e Eucaliptais também se reduziu em cerca de 2,8 ha $(8,4 \%)$. As Galerias Ripícolas mantiveram a expressão que apresentavam em 2001.

A classe de Galerias Ripícolas adota, no presente trabalho, um caráter abrangente de modo a representar igualmente formações vegetais que não revelam um estrato arbóreo contínuo mas que se localizam em margem de albufeira, neste caso na margem do rio Douro, ou ao longo de linhas de drenagem natural, sendo o ribeiro de Covas o exemplo mais representativo. Na proximidade do rio Douro, a vegetação ripícola intercala com matos e com outras culturas das quais os laranjais são o exemplo mais representativo. A dificuldade de estabelecimento de vegetação ripícola na margem do rio Douro pode estar relacionada com a variação do nível de água nas albufeiras, que nesse caso não é muito significativo por se tratarem de aproveitamentos hidroelétricos de "fio de água". Aqui é sobretudo devido ao intenso declive destas margens que rapidamente afastam o terreno do contacto com a água, não estimulando o estabelecimento de espécies lenhosas ripícolas (Cortes, 2008).

Neste local de amostragem foi igualmente registada a presença de vegetação exótica, sobretudo austrália (Acacia melanoxylon), falsa-acácia (Robinia pseudo-acacia) e figueira-da-índia (Opuntia ficus-indica). 


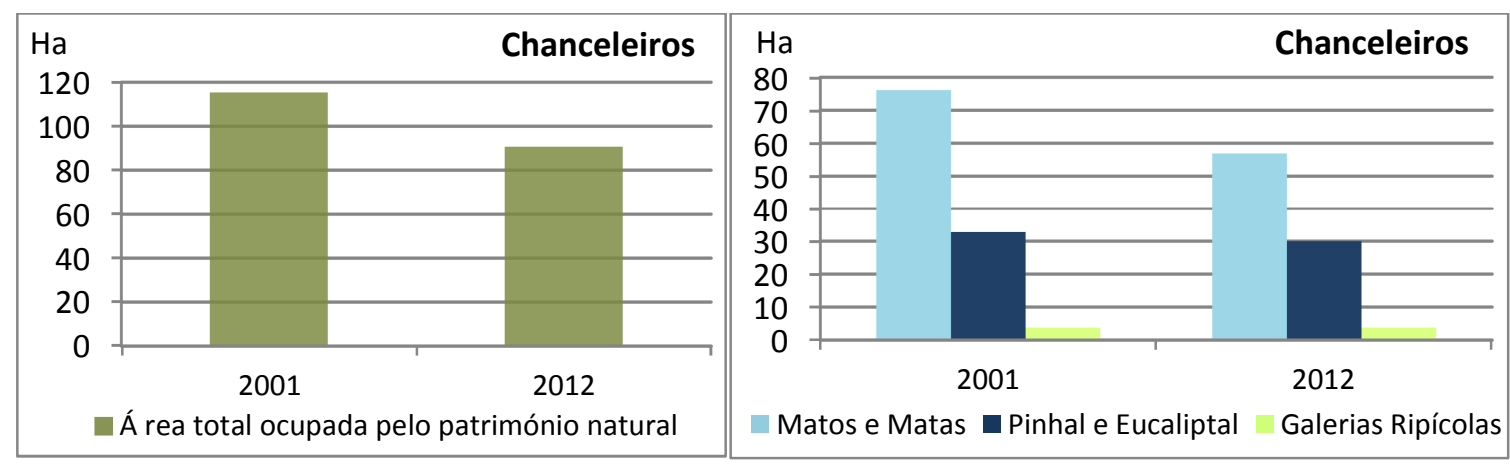

Figura 10 - Variação da área total ocupada pelo património natural nos anos 2001 e 2012, em Chanceleiros; 2) Variação da área ocupada por cada classe de património natural nos anos 2001 e 2012, em Chanceleiros.

\subsection{Avaliação do património natural no Vale do Torto}

No vale do rio Torto nota-se um desequilíbrio na distribuição das manchas de vegetação natural entre a vertente voltada a Norte e a vertente voltada a Sul. Este facto pode estar relacionado com a maior aptidão das propriedades com exposição Sul para a produção vitícola resultando numa maior ocupação do território com esta cultura. Contudo, é ainda possível observar nas cotas mais elevadas parcelas de grande dimensão ocupadas por Matos e Matas. As parcelas que codificam o património natural no vale do rio Torto revelam algumas características distintivas relativamente aos restantes locais de amostragem.

Na Figura 11 observam-se várias manchas de Matos e Matas com uma configuração linear que parece acompanhar as curvas de nível. Estas manchas correspondem a faixas de vegetação que persistiram após plantações de vinha, geralmente "ao alto" ou em patamares, sobre áreas previamente ocupadas por Matos e Matas. A sua forma longilínea deve-se à sua localização ao longo dos acessos principais das propriedades, em taludes mais declivosos que separam os caminhos dos talhões vitícolas. Estas parcelas são geralmente constituídas por arbustos de médio a grande porte, que os agricultores se habituaram a reconhecer atribuindo-Ihes valor cinegético, ornamental ou mesmo de contenção dos solos. É frequente encontrar nestes locais formações de mato alto de onde sobressaem medronheiro (Arbutus unedo), cornalheira (Pistacia therebinthus), lentisco (Phillyrea angustifolia), trovisco (Daphne gnidium) rosmaninho (Lavandula pedunculata) e urzes (Erica spp.). 


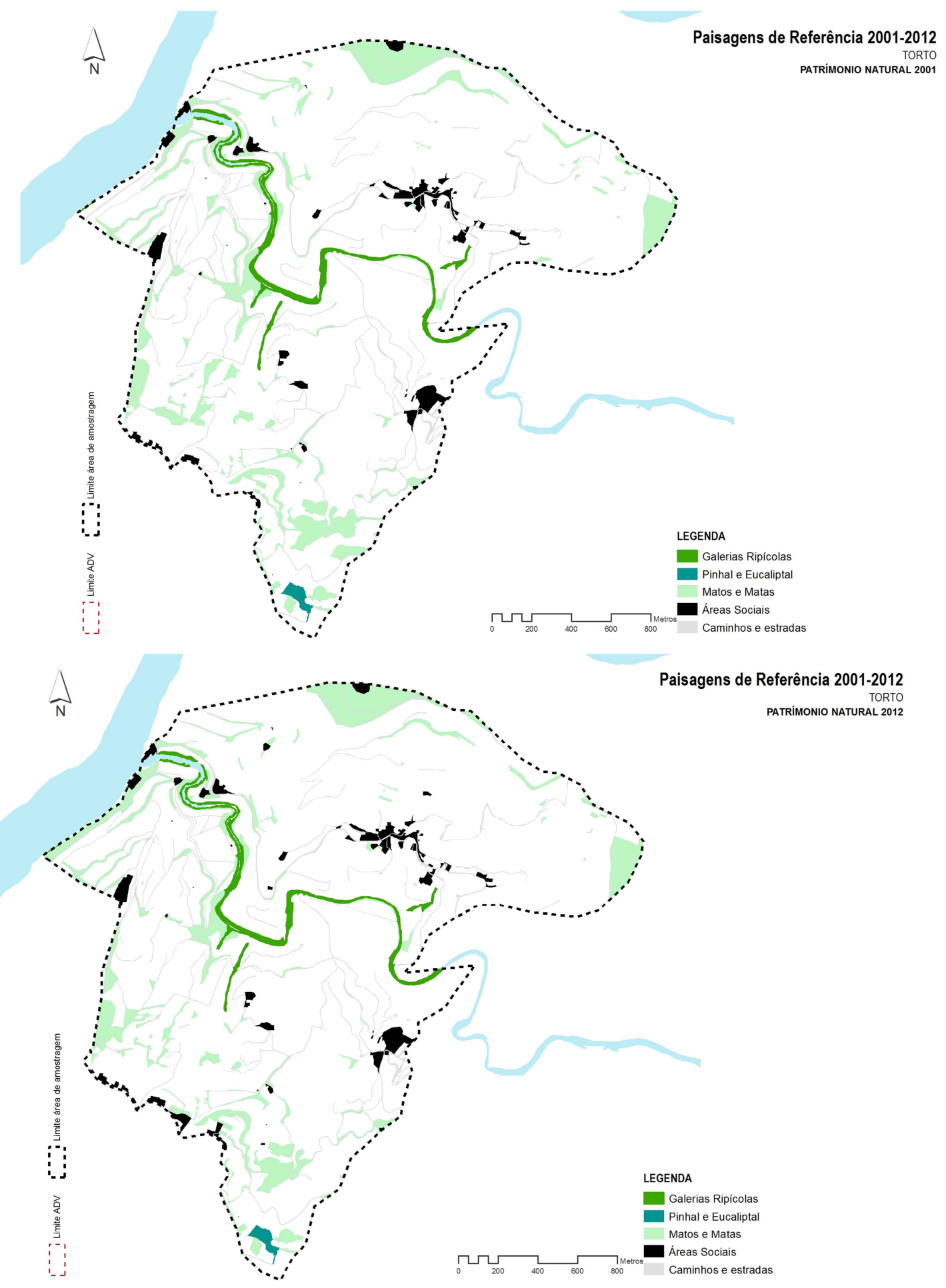

Figura 11 - Carta de património natural do vale do rio Torto, para o cenário temporal 2001 e 2012. 
No vale do rio Torto, entre os anos de 2001 e 2012, não houve perda significativa de área de património natural. Em 2001 as classes que descrevem esse património correspondiam a $10 \%$ da área total do local de amostragem e esse valor mantém-se em 2012.

Neste local de amostragem, a área de património natural atual é quase inteiramente dominada por Matos e Matas (84,3\%), que praticamente já revelavam esta expressão em 2001 (84,7\%). A ligeira perda observada na área ocupada por Matos e Matas deve-se essencialmente à plantação de vinha. A ocupação de Pinhais e Eucaliptais neste local de amostragem é residual (representa 0,2\% da área total de amostragem e 1,97\% da área de património natural) e não sofreu variações o mesmo acontecendo com as Galerias Ripícolas (Figura 12).

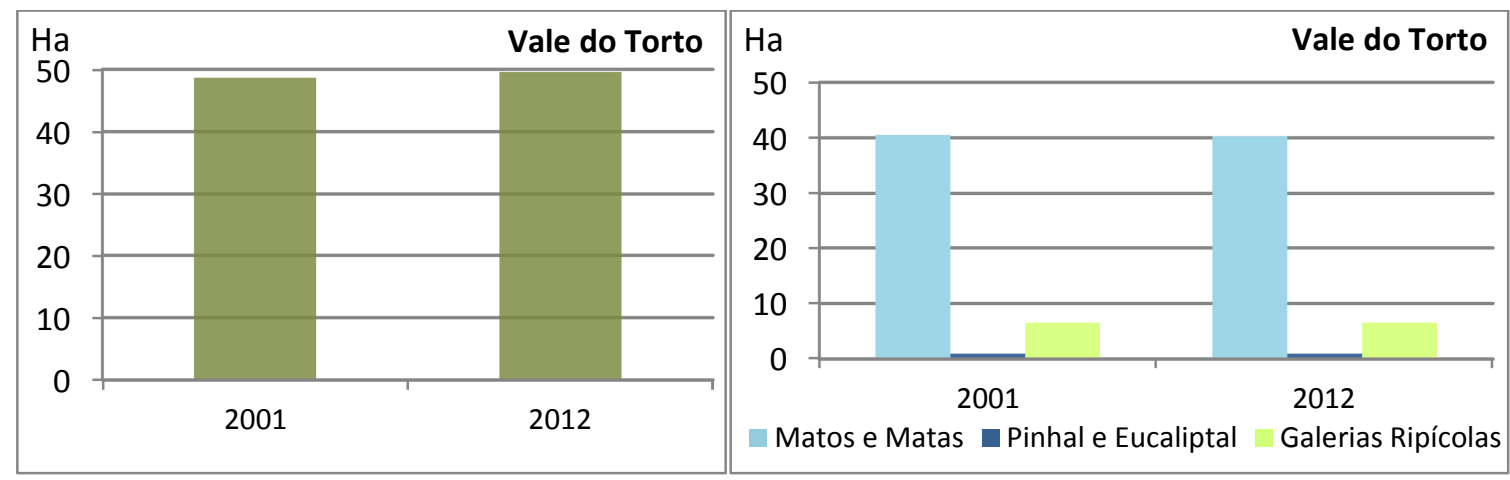

Figura 12 - 1) Variação da área total ocupada pelo património natural nos anos 2001 e 2012, no vale do rio Torto; 2) Variação da área ocupada por cada classe de património natural nos anos 2001 e 2012, no vale do rio Torto.

\subsection{Avaliação do património natural em Vale Figueira}

A vertente voltada a Sul de Vale de Figueira é quase totalmente dominada por Matos e Matas que se desenvolvem sobre afloramentos rochosos e escarpas. Estas parcelas não mostram sinais de ocupação cultural prévia, olival ou vinha, contrariamente ao que se verificava em muitas manchas de Matos e Matos dos outros locais de amostragem. Para este facto podem concorrer vários factores: o posicionamento mais interior de vale de Figueira no contexto do ADV; as difíceis acessibilidades, os elevados declives desta encosta de natureza escarpada, mas sobretudo o tipo de afloramentos rochosos de geologia granítica.

Toda a conjuntura é diferente na encosta voltada a Norte, que revela uma maior ocupação do território com vinha. As Galerias Ripícolas revelam um carácter 
descontínuo, alternado com parcelas de matos. Este comportamento, semelhante ao descrito para a bacia de Chanceleiros, atribui-se da mesma forma à proximidade da linha de caminho e ferro e dificuldade da vegetação arbórea ripícola se estabelecer em margem muito declivosa de albufeira. Contudo, neste local de amostragem a presença de exóticas é menos evidente.

Vale de Figueira revela a maior proporção de área ocupada por património natural de entre todos os locais de amostragem analisados. Em 2001 esse valor era de 160,9 ha correspondendo a 41,1\% da área total, em 2012 passou para 155,7 ha, correspondendo a 39,8 \% da área total. Esta variação aconteceu essencialmente nas áreas de Matos e Matas e em Pinhais e Eucaliptais. Contudo se no primeiro caso as perdas representam apenas uma diminuição de $2,2 \%$ da representatividade da classe, no caso dos Pinhais e Eucaliptais representam uma redução de 48,9\% dessa mesma representatividade (Figura 13). A variação na área de Matos e Matas está sobretudo relacionada com a plantação de vinhas novas, no caso das perdas e com o abandono de olivais e corte de pinheiros no caso das novas áreas de 2012.

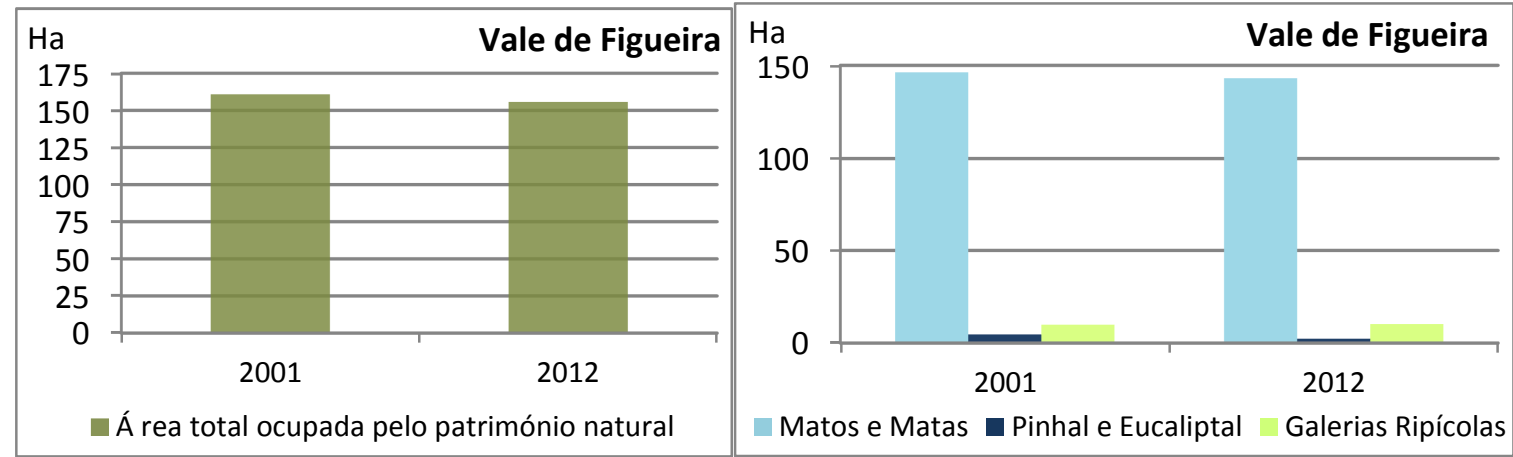

Figura 13 - Variação da área total ocupada pelo património natural nos anos 2001 e 2012, em vale de Figueira; 2) Variação da área ocupada por cada classe de património natural nos anos 2001 e 2012, em vale de Figueira.

\section{Discussão e Conclusões}

Os locais de amostragem analisados em cada uma das paisagens de referência revelaram alguma distinção no que respeita ao seu património natural. Este caráter distintivo observa-se quer ao nível da proporção de espaço ocupado pelas parcelas que o codificam quer ao nível da distribuição e organização espacial dessas parcelas. 
Todos os locais de amostragem tiveram uma variação negativa da área ocupada pelo património natural mas de um modo geral, a diminuição foi pouco significativa: Vale do rio Torto - 0,05\%; Vale de Figueira - 1,3\%; Vale do rio Corgo - 2,5\%; destaca-se Chanceleiros com 5,4\%. A preservação da área de património natural no vale do rio Torto é um dado relevante uma vez que este é o local com menor área de património natural - $10,6 \%$ da área total. Segue-se o vale do rio Corgo com 13,1\%, Chanceleiros com $19,9 \%$ e vale de Figueira onde quase $40 \%$ da área total está ocupada com manchas de vegetação natural.

Nos locais de amostragem analisados, deteta-se uma tendência para a redução da área de património natural que acontece sobretudo à custa da diminuição da área de Matos e Matas e de Pinhal e Eucaliptal. As Galerias Ripícolas tendem a ser preservadas.

Tendo em conta as reflexões anteriores foram encontrados indícios que suscitam alguma atenção relativamente à situação de referência. Salienta-se a redução na área de Matos e Matas e a de Pinhal e Eucaliptal, com consequências assinaláveis para a redução do mosaico paisagístico e tendência para maior homogeneização da paisagem.

A classe de Matos e Matas é muito abrangente englobando desde formações arbustivas pioneiras até comunidades subarbóreas pré-climácicas. Deste modo, temos um conjunto vasto de formações vegetais lenhosas que evidenciam estruturas, composições e combinações florísticas diferentes. Neste contexto, a variação em área desta classe informa essencialmente sobre o seu efeito no mosaico paisagístico e na disponibilidade habitat, mais do que sobre a sua funcionalidade.

Ainda assim, algumas considerações podem ser registadas. Por exemplo, as comunidades arbustivas tendem a revelar uma elevada redundância intercomunitária, ou seja, elevada capacidade de partilha de informação florística com as restantes classes em análise. Esta função será tão mais importante se atendermos aos dados de Fernandes (2009) que indicam que, neste agro-ecossistema, as comunidades arbustivas estabelecem trocas preferenciais com Galerias Ripícolas que são as comunidades que concentram maior diversidade florística. Ainda a este respeito, e se aceitarmos que a redundância é um parâmetro que permite a diferentes taxa apresentarem a mesma funcionalidade, tal como proposto por Loreau (2001), então, podemos deduzir que uma 
elevada redundância intercomunitária, aqui assegurada pela classe de Matos e Matas, confere a este agro-ecossistema uma elevada estabilidade garantindo a funcionalidade dos seus processos ecológicos.

Tendo presente estas informações será fácil perceber que alterações importantes na representatividade da classe de Matos e Matas, pode alterar a funcionalidade do agroecossistema e desse modo a sua capacidade de recuperar o equilíbrio após perturbações.

A diminuição das áreas de Pinhais e Eucaliptais deve igualmente ser acompanhada com alguma preocupação. De facto, em Fernandes (2009) estas formações vegetais revelaram um comportamento claramente divergente em relação às restantes formações vegetais (bosques, comunidades arbustivas, arvenses, ruderais, rupícolas, ripícolas, vinhas e olivais). Este comportamento verificou-se em todas as análises efectuadas permitindo deduzir dois aspectos importantes relativamente ao seu comportamento estrutural e funcionalidade: 1) os pinhais revelaram ser as comunidades com menor redundância intercomunitária, 2) apesar da escassa diversidade florística os pinhais conseguem estabelecer numerosas e diversas combinações florístico-estruturais com a flora disponível revelando uma baixa redundância intracomunitária.

Estes resultados indicam que perante perturbações, os pinhais poderão ter dificuldade em recuperar a sua diversidade específica porque têm dificuldade em partilhar o seu património florístico, ou seja, são comunidades mais frágeis. Mas, por outro lado, a resistência do ecossistema encontra nestas formações um importante conjunto de respostas (em resultado da baixa redundância intracomunitária) que fazem dos pinhais um tipo de formação vegetal importante na gestão da funcionalidade destas paisagens.

As Galerias Ripícolas, graças às condições ecológicas diferenciadoras das restantes comunidades vegetais, têm sido referidas como importantes reservatórios de diversidade florística o que lhes confere capacidades notáveis para a manutenção de um repositório fundamental de informação florística, essencial para a manutenção de mecanismos de resistência e resiliência do ecossistema (Fernandes, 2009). A continuidade do desempenho destas importantes funções parece estar salvaguardada pelo menos no que respeita à disponibilidade de habitat. Contudo, recomenda-se a 
realização de estudos que incidam sobre a composição e estrutura destas formações vegetais no sentido de monitorizar igualmente a sua qualidade ecológica.

Pode-se afirmar que o contributo do património natural nas paisagens de referência analisadas em cada um dos locais de amostragem continua a revelar-se muito importante do ponto de vista da manutenção do caráter de mosaico paisagístico. Apesar das transformações indicadas para o período 2001-2012, estas revelam uma tendência de média-baixa incidência, embora em alguns casos (exo․ Chanceleiros) poderem revelar-se mais expressivas e, por isso, sugerir atenção especial, pelo efeito negativo que demostram com a diminuição do caráter de mosaico, a homogeneização pela expansão expressiva da vinha em patamares, e alguma perda de diversidade sensorial e ecológica.

\section{Referências}

Andresen, T. e Rebelo, J. (2013). Avaliação do Estado de Conservação do Bem Alto Douro Vinhateiro Paisagem Cultural Evolutiva Viva, Volume 1- Relatório de Avaliação. Porto: CCDRN/EMD, CIBIO UP/UTAD.

Bianchi de Aguiar, F.; Andresen, T.; Dias, J; Sousa e Silva, P. (Coord.) (2000) Candidatura do Alto Douro Vinhateiro a Património Mundial. Programa Operacional Regional do Norte e AIBT Douro. Porto.

Bianchi de Aguiar, F.; Andresen, T.; Dias, J.; Sousa e Silva, P. (Coord.) (2001) Plano Intermunicipal de Ordenamento do Território do Alto Douro Vinhateiro - Volume I: Diagnóstico da situação. Vila Real: Universidade de Trás-os-Montes e Alto Douro.

Crespí, A. L., Sampaio e Castro, A., Bernardos, S. (2005) Flora da Região Demarcada do Douro: 2. Sistemática e taxonomia. Mirandela: João Azevedo Editores. 556 p.

Marques, P., Fernandes, C. (2013). A3 - Estado do Património Natural in Avaliação do Estado de Conservação do Bem Alto Douro Vinhateiro - Paisagem Cultural Evolutiva Viva, Volume 2 - Estudos de Base. Porto: CIBIO UP/UTAD: Pp A3.01-A3.29.

Fernandes, C. P. O. (2009). Caracterização e previsão do comportamento florístico-estrutural da vegetação da Região Demarcada do Douro. Tese de Doutoramento em Ciências Exactas, Naturais e Tecnológicas Ciências do Ambiente. Universidade de Trás-os-Montes e Alto Douro. Vila Real. 304 p.

Loreau, M., Naeem, S., Inchausti, P., Bengtsson, J., Grime, J. P., Hector, A., Hooper, D. U., Huston, M. A., Raffaelli, D., Schmid, B., Tilman, D. e Wardle, D. A., (2001). Biodiversity and ecosystem functioning: current knowledge and future challenges. Science, 294: 804-808.

UNESCO (2012). WHC-12/36.COM/7B. United Nations Educational, Scientific And Cultural Organization. Convention Concerning The Protection Of The World Cultural And Natural Heritage. World Heritage Committee. Saint-Petersburg, Russian Federation.

UNESCO (2013). WHC. 13/01. Operational Guidelines for the Implementation of the World Heritage Convention. United Nations Educational, Scientific And Cultural Organization. Intergovernmental committee for the protection of the world cultural and natural heritage.

Ribeiro, J. A. e Diniz, A. C. (2004). A vegetação natural de Trás-os-Montes e Alto Douro. Estudos Transmontanos, 11.

Ribeiro, J. A. (2000). Flora e Vegetação Ribeirinha. Douro - Estudos \& Documentos 5 (9): 39-45.

http://www.icnf.pt/ 